Bull. Chem. Soc. Ethiop. 2018, 32(2), 185-197.

ISSN 1011-3924

(c) 2018 Chemical Society of Ethiopia and The Authors

Printed in Ethiopia

DOI: https://dx.doi.org/10.4314/bcse.v32i2.1

\title{
LEVELS OF SELECTED METALS IN THE LEAVES OF RUTA CHALEPENSIS L. (RUE) COLLECTED FROM FOUR DIFFERENT AREAS OF ETHIOPIA
}

\author{
Solomon Admasu, Bhagwan Singh Chandravanshi ${ }^{*}$ and Weldegebriel Yohannes \\ Department of Chemistry, College of Natural Sciences, Addis Ababa University, P. O. Box \\ 1176, Addis Ababa, Ethiopia
}

(Received April 23, 2018; Revised July 10, 2018; Accepted July 16, 2018)

\begin{abstract}
The objective of this study was to determine the level of selected metals in the leaves of Ruta chalepensis L. (Rue) cultivated in Ethiopia. Rue leaves samples were randomly collected from four different parts of Ethiopia (Kality and Alem Bank from Addis Ababa Administration, Holeta (Oromia Region) and Worabe (South Nations and Nationalities Peoples Region)). A $0.5 \mathrm{~g}$ Rue sample was digested with $3.0 \mathrm{~mL}$ of $69.5 \% \mathrm{HNO}_{3}$ and $1.0 \mathrm{~mL} 70 \% \mathrm{HClO}_{4}$ and the levels of selected metals were determined by flame atomic absorption spectrometry. The validity of the optimized procedure was evaluated by analyzing the digest of the spiked samples with standard solution and the percentage recoveries varied from 92.0 to $102 \%$. The levels of metals determined in $\mathrm{mg} / \mathrm{kg}$ dry weight were in the ranges $\mathrm{Ca}(1872-3077), \mathrm{Zn}(44.5-64.0), \mathrm{Cu}(<\mathrm{DL}-10.8), \mathrm{Cr}(<\mathrm{DL}-3.10)$ and $\mathrm{Cd}$ $(<\mathrm{DL}-2.87)$ (where $\mathrm{DL}$ is detection limit). $\mathrm{Ni}$ and $\mathrm{Pb}$ were below the detection limit. ANOVA at $\mathrm{p}=0.05$ indicated that there is a significant difference in the level of $\mathrm{Ca}, \mathrm{Cr}, \mathrm{Cu}$ and $\mathrm{Zn}$ in the samples. The results indicate that the content of the metals did not exceed the permissible amount for medicinal plants set by WHO and FAO.
\end{abstract}

KEY WORDS: Ruta chalepensis L., Rue, Tena Adam, Metals, Flame atomic absorption spectrometry, Ethiopia

\section{INTRODUCTION}

Ruta chalepensis L. (Rue) is an herbaceous perennial, originally native to the Mediterranean region and the Canary Islands. It has blue-green foliage and yellow flowers. This plant is a hardy, evergreen shrub of up to $1 \mathrm{~m}$ tall, with a characteristic grayish color and a sharp unpleasant odor. The leaves are small, oblong, deeply divided, and pinnate; and the stems are ramified. It belongs to the family Rutaceeae and is a shrubby plant [1].

It is now cultivated in many parts of the world. In tropical Africa it has been introduced and naturalized in several countries, including the Cape Verde Islands, Sudan, Ethiopia, Somalia and Southern Africa (including South Africa), where it is mostly cultivated in herbal gardens. The morphologically and chemically related $R$. graveolens $\mathrm{L}$. seems only to be present in South Africa [2].

$R$. chalepensis grows well in well-drained sandy or rocky limestone soils and prefers an open sunny position. In Ethiopia it is cultivated at 1500-2000 m altitude. In Ethiopia and South Africa $R$. chalepensis flowers and fruits are commonly planted in home gardens. Plants growing at lower altitudes in tropical Africa do not often flower, so the plants are vegetatively multiplied and the genetic variation might therefore be on the low side for these plants [2].

The essential oils from aerial parts of $R$. chalepensis plants harvested at different stages of growth in northern India contained 19 components, representing $85.4-93.3 \%$ of the oil. The major components were 2-undecanone (41.3-67.8\%), 2-nonanone (5.2-33.6\%), 2-nonyl-acetate $(2.8-15.3 \%)$ and 2-dodecanone $(<0.1-11.6 \%)$ [2]. Major compounds isolated from the roots of $R$. chalepensis are the furoquinolin alkaloids kokusaginin, skimmianin and graveolin, the acridone alkaloids 1-hydroxy-N-methylacridone and chaloridon, and the furanocoumarin chalepensin. From the dried aerial parts, major compounds isolated include the furoquinolin alkaloids kokusaginin, skimmianin, graveolin, $\gamma$-fagarin and dictamnin, the acridone alkaloid arborinin, and the (furano-)coumarins bergapten (or 5-methoxypsoralen) and chalepensin [2].

*Corresponding author. E-mail: bscv2006@yahoo.com

This work is licensed under the Creative Commons Attribution 4.0 International License 
$R$. chalepensis is used for cooking and medicinal purposes. The medicinal and culinary properties are attributed to the presence of essential oils which are contained in all parts of the plant. It is known that herbal and medicinal plants have been used for treatment of diseases, especially in the developing countries. For example, R. chalepensis has been in popular herbalism in various countries to treat a variety of ailments [3]. Moreover, it was reported that the methanolic extract of $R$. chalepensis has antibacterial activity, and the essential oil of $R$. chalepensis L. has antioxidant activities. Thus, contamination of edible medicinal plants by toxic metals is a threat for human health [4].

In Ethiopia, the Amharic name of $R$. chalepensis L. is Tena Adam literally means health of Adam, thus signifying the medicinal applications of the plant. In Ethiopian folk medicine, it is used to treat colicky babies, diarrhea, earache, heart pain, hemorrhoids, influenza symptoms and intestinal disorders. The dried and ground fruits are boiled and taken by mouth for diarrhea. The juice from the crushed leaves is mixed with water and administered to colicky babies. The ground plant material is made into an ointment to be used for hemorrhoids. The boiled plant is used to treat influenza symptoms [5].

In addition to medicinal applications; the leaves of $R$. chalepensis are used to flavor sour milk and cheese and used commonly as spice or dipped/stirred during a traditional Ethiopian coffee and tea ceremony. They are also used to flavor "kuti" which is used as a hot beverage brewed from coffee leaves. The fruits are used as ingredients of the local "berbere" and "mitten shiro" spice mix. The volatile aromatic constituents may be responsible for the flavor of the plant [6]. In North Africa, an infusion of Rue is used for colds, earaches and intestinal problems. Due to its strong smell, the fresh plant is used as a scorpion repellant. In Algiers, the infusion of the plant is used as nose drops to treat vomiting and fevers in children [7].

Environmental pollution, especially with heavy metals, poses serious problem on the quality of medicinal plants and their products. Thus, the element content assessment is important for specifying the relevance of application to produce drugs [4].

Food is the major intake source of toxic trace elements by human beings. Vegetables, fish, meat, grains, soft drinks, condiments, etc. are used as staple part of food. Various studies investigated the concentration of major, minor, and trace elements from the different items of food. Vegetables [8,9], food condiments [10], water [11], bread [12] and fish [13] are some among others.

Recently, some studies have been reported on the levels of metals in vegetables [14-16], fruits [17, 18] and spices [19-24] consumed in Ethiopia. A few studies have also been done on the levels of metals in medicinal plants [25-27]. However, only two studies have been reported on the levels of metal concentration of $R$. chalepensis species, one by Baye and Hymete [28] in Ethiopia, who determined $\mathrm{Pb}$ and $\mathrm{Cd}$ accumulation by graphite furnace atomic absorption spectrophotometer (GFAAS) and the other by Massadeha et al. [4] in Jordan, who determined heavy metals such as $\mathrm{Pb}, \mathrm{Cu}, \mathrm{Zn}, \mathrm{Cd}, \mathrm{Ni}$, and $\mathrm{Fe}$ by atomic absorption spectrometry (AAS) in different parts of $R$. chalepensis. There is no reported data about the level of other metals in $R$. chalepensis grown in Ethiopia.

The objective of this research was to determine selected metals $(\mathrm{Ca}, \mathrm{Cr}, \mathrm{Cu}, \mathrm{Zn}, \mathrm{Ni}, \mathrm{Cd}$ and $\mathrm{Pb}$ ) in Rue (Ruta chalepensis L.) plant cultivated in four different areas of Ethiopia. The metals for this study were selected based on their relative significance. $\mathrm{Cd}$ and $\mathrm{Pb}$ were selected as toxic metals; $\mathrm{Ni}$ was also selected as a toxic metal to some extent; $\mathrm{Cr}, \mathrm{Cu}$ and $\mathrm{Zn}$ were selected as essential trace metals and $\mathrm{Ca}$ was selected as a major essential metal. More metals were not selected because AAS does not allow simultaneous determination of metals in a single run. The specific objectives of this research were to: (i) develop and validate sample preparation procedure for the extraction of selected trace metals from Rue ( $R$. chalepensis L.) for their subsequent determination by using flame atomic absorption spectrometry (FAAS), (ii) determine some selected trace metals found in Rue (R. chalepensis L.) by using flame atomic absorption spectrophotometry (FAAS), (iii) compare the levels of the identified metals in Rue 
(R. chalepensis L.) in four different areas of Addis Ababa, Ethiopia, and (iv) compare the levels of the identified metals in Rue ( $R$. chalepensis L.) in four different areas of Ethiopia with that of the data reported in the literature.

\section{EXPERIMENTAL}

\section{Instrument and apparatus}

Ceramic pestle and mortar were used for grinding and homogenizing the dried Rue leaves; digital analytical balance (Mettler Toledo, Model AT250, Switzerland) with $\pm 0.0001 \mathrm{~g}$ precision was used for weighing the samples. Quick-fit round bottom flasks $(250 \mathrm{~mL})$ fitted with reflux condenser were used in Kjeldahl apparatus hot plate to digest the samples. A refrigerator (Hitachi, Tokyo, Japan) was used to keep the samples ready for analysis. $2 \mathrm{~mL}, 5 \mathrm{~mL}$, and 10 $\mathrm{mL}$ pipettes and a micropipette (Dragonmed, Shanghai, China) were used for measuring different amounts of acids and standard solutions and for spiking of known concentration for recovery test. $25 \mathrm{~mL}$ and $100 \mathrm{~mL}$ volumetric flasks were used to dilute sample solutions and prepare standard solutions. ZEEnit 700p scientific model Analytik Jena (Germany) flame atomic absorption spectrometer equipped with deuterium arc background corrector using air-acetylene flame was used for analysis of the metals $(\mathrm{Ca}, \mathrm{Cr}, \mathrm{Cu}, \mathrm{Zn}, \mathrm{Ni}, \mathrm{Cd}$ and $\mathrm{Pb})$.

\section{Chemicals, reagents and standard solutions}

All the reagents used were of analytical grade and all standard solutions are CRM (certified reference material). For digestion of Rue leaf samples, $69.5 \% \mathrm{HNO}_{3}$ (Scharlau, Spain) and 70\% $\mathrm{HClO}_{4}$ (Research-lab fine chem industries, Mumbai, India) were used. Stock standard solutions of the metals $(\mathrm{Ca}, \mathrm{Cr}, \mathrm{Cu}, \mathrm{Zn}, \mathrm{Ni}, \mathrm{Cd}$ and $\mathrm{Pb} 1,000 \mathrm{mg} / \mathrm{L}$ calibration standards Buck Scientific, USA, prepared as nitrates for each element in $2 \% \mathrm{HNO}_{3}$ ) were used for the preparation of calibration curves for the determination of metals in the samples. Distilled-deionized water was throughout the experimental work.

\section{The study areas}

The leaf samples of Rue ( $R$. chalepensis L.) were collected randomly from four different areas of Ethiopia. Out of the four samples two samples were collected from gardens located in Addis Ababa Administration around Kality and Alem Bank with full permission of owners. Another two samples were collected from Oromia region around Holeta and South Nations and Nationalities Peoples Region around Worabe. The selection of sample collection areas in four different parts of Ethiopia were based upon mainly accessibility for sampling and potential area for the plant Rue ( $R$. chalepensis L.) cultivation. Geographical description of sample collection sites is given in Table 1 .

Table 1. Geographical description of sample collection sites.

\begin{tabular}{|c|c|c|c|c|c|c|c|}
\hline No. & Sample sites & Region & \multicolumn{5}{|c|}{ Approximate geographical locations } \\
\cline { 4 - 8 } & & Latitude & Longitude & $\begin{array}{c}\text { Altitude above } \\
\text { sea level }(\mathrm{m})\end{array}$ & $\begin{array}{c}\text { Distance from } \\
\text { Addis Ababa (km) }\end{array}$ & $\begin{array}{c}\text { Direction from } \\
\text { Addis Ababa }\end{array}$ \\
\hline 1 & Kality & AAA & $9^{\circ} 01^{\prime} 29^{\prime \prime} \mathrm{N}$ & $38^{\circ} 44^{\prime} 48^{\prime \prime} \mathrm{E}$ & 2405 & 14 & East \\
\hline 2 & Holeta & Oromia & $9 \hat{\mathrm{A}}^{\circ} 3 \mathrm{~N}$ & $38 \hat{\mathrm{A}}^{\circ} 30 \mathrm{E}$ & 2391 & 37 & North West \\
\hline 3 & Alem Bank & AAA & $9^{\circ} 01^{\prime} 29^{\prime \prime} \mathrm{N}$ & $38^{\circ} 44^{\prime} 48^{\prime \prime} \mathrm{E}$ & 2405 & 4 & West \\
\hline 4 & Worabe & SNNPR & $8 \hat{\mathrm{A}}^{\circ} 1 \mathrm{~N}$ & $38 \hat{\mathrm{A}}^{\circ} 20 \mathrm{E}$ & 2113 & 169 & South \\
\hline
\end{tabular}

AAA = Addis Ababa Administration and SNNPR = Southern Nations, Nationalities, and Peoples' Region. 
Collection of samples

Leaves of Rue ( $R$. chalepensis L.) $(0.5 \mathrm{~kg}$ from each site) were collected by using random sampling technique [29] from the study areas. All the leaf samples from four different areas of Ethiopia were stored in clean polyethylene plastic bags separately and transported to the laboratory and stored at room temperature $\left(22 \pm 2{ }^{\circ} \mathrm{C}\right)$ prior to sample preparation, digestion and analysis.

\section{Sample preparation for elemental analysis}

The leaves of the plant were washed well with the running tap water and rinsed first with distilled water and then with deionized water to remove earthy impurities, allowed to dry in air for ten days, chopped and ground to powder with mortar and pestle. The powdered samples were screened with 100 mesh sieve and stored in dry, clean and closely packed polyethylene plastic bag until digestion. Finally, $0.5 \mathrm{~g}$ aliquot was taken from each sample for digestion and a solution for final metal determination was prepared.

\section{Optimization of digestion procedure}

To select an optimum procedure for digestion, parameters like digestion time, reagent volume, volume ratio of reagents, and digestion temperature were optimized by varying one parameter at a time and keeping the others constant. Parameters giving clear solution at lower temperature, requiring minimum reagent volume and digestion time were selected as an optimum procedure for digestion of Rue sample. Finally, the optimum procedure was chosen on the basis of these criteria requiring three hours for complete digestion of $0.5 \mathrm{~g}$ Rue sample with $3.0 \mathrm{~mL}$ of $69.5 \%$ $\mathrm{HNO}_{3}$ and $1.0 \mathrm{~mL} 70 \% \mathrm{HClO}_{4}$ as given in Table 2.

Table 2. Optimization of digestion procedure using $0.5 \mathrm{~g}$ Rue leaves samples.

\begin{tabular}{|c|c|c|c|c|}
\hline No. & $\begin{array}{c}\text { Volume of reagents } \\
(\mathrm{mL})\end{array}$ & $\begin{array}{c}\text { Digestion } \\
\text { temperature }\left({ }^{\circ} \mathrm{C}\right)\end{array}$ & $\begin{array}{c}\text { Digestion } \\
\text { time }(\mathrm{h})\end{array}$ & Results after filtration and dilution \\
\hline 1 & $2: 2 \mathrm{~mL}\left(\mathrm{HNO}_{3}: \mathrm{HClO}_{4}\right)$ & 240 & 3 & Yellow solution with residue \\
\hline 2 & $2: 2 \mathrm{~mL}\left(\mathrm{HNO}_{3}: \mathrm{HClO}_{4}\right)$ & 270 & 3 & Pale yellow clear solution \\
\hline 3 & $2: 2 \mathrm{~mL}\left(\mathrm{HNO}_{3}: \mathrm{HClO}_{4}\right)$ & 300 & 3 & Pale yellow clear solution \\
\hline 4 & $2.5: 2.5 \mathrm{~mL}\left(\mathrm{HNO}_{3}: \mathrm{HClO}_{4}\right)$ & 300 & 3 & Pale yellow clear solution \\
\hline 5 & $3: 3 \mathrm{~mL}\left(\mathrm{HNO}_{3}: \mathrm{HClO}_{4}\right)$ & 300 & 3 & Pale yellow clear solution \\
\hline 6 & $3: 3 \mathrm{~mL}\left(\mathrm{HNO}_{3}: \mathrm{HClO}_{4}\right)$ & 300 & 3.5 & Colorless clear solution \\
\hline 7 & $3: 1 \mathrm{~mL}\left(\mathrm{HNO}_{3}: \mathrm{HClO}_{4}\right)$ & 240 & 3.5 & Yellow solution with residue \\
\hline 8 & $3: 1 \mathrm{~mL}\left(\mathrm{HNO}_{3}: \mathrm{HClO}_{4}\right)$ & 270 & 3.5 & Pale yellow clear solution \\
\hline 9 & $3: 1 \mathrm{~mL}\left(\mathrm{HNO}_{3}: \mathrm{HClO}_{4}\right)$ & 300 & 3.5 & Pale yellow clear solution \\
\hline $\mathbf{1 0}$ & $\mathbf{3 : 1 ~} \mathbf{~ m L ~}\left(\mathrm{HNO}_{3}: \mathrm{HClO}_{4}\right)$ & $\mathbf{3 0 0}$ & $\mathbf{3}$ & Colorless clear solution (Optimum) \\
\hline
\end{tabular}

Bold font (No. 10) indicates optimized volume, temperature and time.

\section{Digestion of leaves of Rue samples}

Applying the optimized procedure given above, $0.5 \mathrm{~g}$ of powdered rue sample was placed in a $250 \mathrm{~mL}$ round bottom flask. To this, $3 \mathrm{~mL}$ of $\mathrm{HNO}_{3}(69.5 \%)$ and $1 \mathrm{~mL}$ of $\mathrm{HClO}_{4}(70 \%)$ was added. The round bottom flask was fitted to a reflux condenser and heated on a Kjeldahl apparatus hot plate for $3 \mathrm{~h}$ at a temperature of $300{ }^{\circ} \mathrm{C}$. The digest was allowed to cool for $10 \mathrm{~min}$ without dismantling the condenser and then further cooled to room temperature for $20 \mathrm{~min}$ by dismantling the condenser. The mixture was diluted with $10 \mathrm{~mL}$ of distilled-deionized water and filtered with Whatman filter paper No. 42 into a $25 \mathrm{~mL}$ volumetric flask. The round bottom flask was further rinsed with $5 \mathrm{~mL}$ of distilled-deionized water and added to the filtrate. Then 
$1 \%$ of $\mathrm{La}\left(\mathrm{NO}_{3}\right)_{3} \cdot 6 \mathrm{H}_{2} \mathrm{O}$ was added to the flask containing the filtrate the flask was filled to the mark with deionized water. $\mathrm{La}\left(\mathrm{NO}_{3}\right)_{3} \cdot 6 \mathrm{H}_{2} \mathrm{O}$ was added was to prevent the precipitation of $\mathrm{Ca}^{+2}$ with the $\mathrm{SO}_{4}{ }^{-2}$ and $\mathrm{PO}_{4}^{-3}$ if they were present in the samples or the reagents used in the process.

For each sample the digestion was done in triplicate. Triplicate blank samples, a mixture of $3 \mathrm{~mL}$ of $\mathrm{HNO}_{3}$ and $1 \mathrm{~mL}$ of $\mathrm{HClO}_{4}$ were also digested following the same procedure as the samples. Finally, all the digests were kept in refrigerator until FAAS analysis.

\section{Calibration of the instrument}

$10 \mathrm{mg} / \mathrm{L}$ intermediate standard solutions of metals of interest were prepared from the atomic absorption spectroscopy standard stock solutions that contained $1000 \mathrm{mg} / \mathrm{L}$. The intermediate standard solutions were diluted with deionized water to obtain four working standards of each metal, i.e. $\mathrm{Ca}, \mathrm{Cr}, \mathrm{Cu}, \mathrm{Zn}, \mathrm{Cd}, \mathrm{Ni}$ and $\mathrm{Pb}$. The absorbances of the working standard solutions were measured and the calibration curves for each of the analyte metal $(\mathrm{Ca}, \mathrm{Cr}, \mathrm{Cu}, \mathrm{Zn}, \mathrm{Cd}, \mathrm{Ni}$ and $\mathrm{Pb}$ ) were constructed. The wavelength, calibration standard concentrations, correlation coefficient and equation of the calibration curves for determination of metals using FAAS are given in Table 3. The correlation coefficients in Table 3 clearly indicate that the change in absorbance with concentration is in good positive correlation and are linearly fit.

\section{Determination of the metals by FAAS}

The levels of each metal in all the samples were determined with FAAS after the instrumental operating conditions were optimized for maximum signal intensity of the instrument. Triplicate determinations were carried out on each sample. The same analytical procedure was employed for the determination of elements in the digested blank solutions.

Table 3. Wavelengths, calibration standard concentrations, correlation coefficients and equations of the calibration curves for determination of metals using FAAS.

\begin{tabular}{|c|c|c|c|c|}
\hline Metal & $\begin{array}{c}\text { Wavelength } \\
(\mathrm{nm})\end{array}$ & $\begin{array}{c}\text { Working standard concentrations } \\
(\mathrm{mg} / \mathrm{L})\end{array}$ & $\begin{array}{c}\text { Correlation coefficient } \\
\left(\mathrm{R}^{2}\right)\end{array}$ & $\begin{array}{c}\text { Equation of the } \\
\text { calibration curves }\end{array}$ \\
\hline $\mathrm{Ca}$ & 422.7 & $0.15,0.25,0.50,1.00$ & 0.9964 & $\mathrm{y}=0.0288 \mathrm{x}+0.0011$ \\
\hline $\mathrm{Cr}$ & 357.9 & $0.50,1.00,1.50,2.00$ & 0.9985 & $\mathrm{y}=0.0138 \mathrm{x}-0.0006$ \\
\hline $\mathrm{Cu}$ & 324.8 & $0.25,0.50,1.00,2.00$ & 0.9910 & $\mathrm{y}=0.0192 \mathrm{x}-7 \times 10^{-5}$ \\
\hline $\mathrm{Zn}$ & 213.9 & $0.25,0.50,0.75,1.00$ & 0.9985 & $\mathrm{y}=0.087 \mathrm{x}+0.0032$ \\
\hline $\mathrm{Cd}$ & 228.8 & $0.25,0.50,0.75,1.00$ & 0.9967 & $\mathrm{y}=0.0503 \mathrm{x}-0.0013$ \\
\hline $\mathrm{Ni}$ & 232.0 & $0.5,1.5,3.00,6.00$ & 0.9990 & $\mathrm{y}=0.0069 \mathrm{x}-0.0007$ \\
\hline $\mathrm{Pb}$ & 283.3 & $0.40,0.80,1.20,1.60$ & 0.9978 & $\mathrm{y}=0.0037 \mathrm{x}-0.0003$ \\
\hline
\end{tabular}

Precision and accuracy

The precision of an analytical procedure expresses the closeness or agreement (degree of scatter) between a series of measurements obtained from multiple sampling of the same homogeneous sample under the prescribed conditions [30]. In this study the results of the measurements are expressed as the mean of the triplicate measurements together with the standard deviation of each sample.

Validation of the optimized procedure [29]

Spiking experiments were performed to validate the optimized procedure. For this purpose, standard solutions of $1,000 \mathrm{mg} / \mathrm{L}$ each metal were used and intermediate standards of $100 \mathrm{mg} / \mathrm{L}$ of each metal $(\mathrm{Ca}, \mathrm{Cr}, \mathrm{Cu}, \mathrm{Zn}, \mathrm{Cd}, \mathrm{Ni}$ and $\mathrm{Pb})$ were prepared from $1,000 \mathrm{mg} / \mathrm{L}$ standard stock solution. For recovery measurement the sample from Worabe was selected and the spiking was 
done in two groups in triplicate. That is, in the first group $50 \mu \mathrm{L}$ of $\mathrm{Cr}, 25 \mu \mathrm{L}$ of $\mathrm{Cu}, 64 \mu \mathrm{L}$ of $\mathrm{Zn}, 25 \mu \mathrm{L}$ of $\mathrm{Cd}, 75 \mu \mathrm{L}$ of $\mathrm{Ni}$ and $40 \mu \mathrm{L}$ of $\mathrm{Pb}$ respectively were spiked together and added into $250 \mathrm{~mL}$ round bottomed flask containing $0.5 \mathrm{~g}$ sample and $4 \mathrm{~mL}$ of acid mixture $\left(3 \mathrm{~mL} \mathrm{HNO}_{3}\right.$ and $1 \mathrm{~mL}$ of $\mathrm{HClO}_{4}$ ) and in the second group $3077 \mu \mathrm{L}$ of $\mathrm{Ca}$ was spiked and added into round bottomed flasks containing the same amount of sample and acid. The round bottomed flasks containing the mixtures were fitted with the condenser and digested simultaneously with unspiked samples on a hot plate Kjeldahl apparatus by applying the optimized digestion procedure used in sample analysis. The percentage recoveries of the analytes were calculated. The results of recovery analysis are listed in Table 4 . The percentage recoveries lie within the range 92.0$102 \%$. The percentage recovery for Rue samples are within the acceptable range for all the metals.

Table 4. Recovery of metals in the leaves of Rue determined using the optimized digestion procedure.

\begin{tabular}{|c|c|c|c|c|}
\hline Metal & $\begin{array}{c}\text { Concentration of metal in } \\
\text { un-spiked sample }(\mathrm{mg} / \mathrm{L})\end{array}$ & $\begin{array}{c}\text { Amount spiked } \\
(\mathrm{mg} / \mathrm{L})\end{array}$ & $\begin{array}{c}\text { Concentration of metal in } \\
\text { spiked sample (mg/L) }\end{array}$ & \% Recovery \pm SD \\
\hline $\mathrm{Ca}$ & 61.4 & 12.3 & 73.3 & $96.7 \pm 5.6$ \\
\hline $\mathrm{Cr}$ & $<\mathrm{DL}$ & 0.2 & 0.197 & $98.6 \pm 5.5$ \\
\hline $\mathrm{Cu}$ & $<\mathrm{DL}$ & 0.1 & 0.097 & $96.5 \pm 5.9$ \\
\hline $\mathrm{Zn}$ & 1.3 & 0.26 & 1.53 & $96.9 \pm 9.7$ \\
\hline $\mathrm{Cd}$ & $<\mathrm{DL}$ & 0.1 & 0.099 & $98.7 \pm 2.8$ \\
\hline $\mathrm{Ni}$ & $<\mathrm{DL}$ & 0.3 & 0.28 & $92.0 \pm 7.4$ \\
\hline $\mathrm{Pb}$ & $<\mathrm{DL}$ & 0.16 & 0.162 & $102 \pm 10$ \\
\hline
\end{tabular}

DL - detection limit.

\section{RESULTS AND DISCUSSION}

Levels of metals in the leaves of Rue samples

The developed FAAS method was applied for the determination of the levels of seven metals $(\mathrm{Ca}, \mathrm{Cr}, \mathrm{Cu}, \mathrm{Zn}, \mathrm{Cd}, \mathrm{Ni}$ and $\mathrm{Pb})$ in leaves of Rue samples collected from four different areas of Ethiopia, i.e., Kality (Addis Ababa Administration), Holeta (Oromia Region), Alem Bank (Addis Ababa Administration) and Worabe (South Nations and Nationalities Peoples Region). The mean values were determined from triplicate analysis of each sample and the accuracy and precision of the results were checked by the aid of different statistical methods after the determination of the levels of metals in the Rue samples. Results obtained for each sample in terms of $\mathrm{mg} / \mathrm{kg}$ dry weight basis together with values for standard deviation are given in Table 5 .

Table 5. Mean concentration and standard deviation (mean $\pm \mathrm{mg} / \mathrm{kg}$ ) of selected metals in each sample analyzed by FAAS.

\begin{tabular}{|c|c|c|c|c|c|c|}
\hline \multirow[t]{2}{*}{ No. } & \multirow[t]{2}{*}{ Metal } & \multicolumn{4}{|c|}{ Sample sites, concentration (mean \pm SD) in $\mathrm{mg} / \mathrm{kg}$} & \multirow{2}{*}{$\begin{array}{c}\text { Range of metal } \\
\text { concentration }(\mathrm{mg} / \mathrm{kg})\end{array}$} \\
\hline & & Kality & Holeta & Alem Bank & Worabe & \\
\hline 1 & $\mathrm{Ca}$ & $2409 \pm 1.0$ & $1872 \pm 2.0$ & $2443 \pm 2.0$ & $3077 \pm 1.0$ & $1872-3077$ \\
\hline 2 & $\mathrm{Cr}$ & $3.10 \pm 0.04$ & $1.20 \pm 0.02$ & $1.70 \pm 0.03$ & $<\mathrm{DL}$ & $<\mathrm{DL}-3.10$ \\
\hline 3 & $\mathrm{Cu}$ & $5.80 \pm 0.06$ & $<\mathrm{DL}$ & $10.8 \pm 0.02$ & $<\mathrm{DL}$ & $<\mathrm{DL}-10.8$ \\
\hline 4 & $\mathrm{Zn}$ & $49.1 \pm 0.06$ & $44.5 \pm 0.02$ & $60.8 \pm 0.5$ & $63.9 \pm 0.10$ & $44.5-63.9$ \\
\hline 5 & $\mathrm{Cd}$ & $2.90 \pm 0.03$ & $<\mathrm{DL}$ & $<\mathrm{DL}$ & $<\mathrm{DL}$ & $<\mathrm{DL}-2.90$ \\
\hline 6 & $\mathrm{Ni}$ & $<\mathrm{DL}$ & $<\mathrm{DL}$ & $<\mathrm{DL}$ & $<\mathrm{DL}$ & $<\mathrm{DL}$ \\
\hline 7 & $\mathrm{~Pb}$ & $<\mathrm{DL}$ & $<\mathrm{DL}$ & $<\mathrm{DL}$ & $<\mathrm{DL}$ & $<\mathrm{DL}$ \\
\hline
\end{tabular}

$\mathrm{DL}=$ detection limit. ANOVA at $\mathrm{p}=0.05$ indicated significant difference in the mean vales of each metal among the sampling sites. 
Levels of selected metals in the leaves of Ruta chalepensis L. (Rue) cultivated in Ethiopia 191

\section{Distribution patterns of metals in the samples}

As indicated in the Table 5 metals $\mathrm{Ca}$ and $\mathrm{Zn}$ were found in all the samples and metals $\mathrm{Ni}$ and $\mathrm{Pb}$ were below detection limit of the instrument in all the samples. $\mathrm{Cr}$ was found in all samples except in the sample from Worabe, $\mathrm{Cu}$ was found in Kality and Alem Bank Rue leaves and $\mathrm{Cd}$ was found only in Rue leaves from Kality.

The results of this study showed that the metal contents of Rue leaves varied with the geographical origin in which the Rue plant grows. There are industrial activities in samples collected from Addis Ababa Administration, especially Kality areas. Because of this $\mathrm{Cr}, \mathrm{Cu}$ and $\mathrm{Cd}$ were detected in the samples from Addis Ababa while these metals were not detected in the area outside Addis Ababa like Worabe. The natural weathering of rocks, agricultural activities like using fertilizer, pesticide, and water for irrigation could contribute to these concentrations of metals determined in Rue leaves. A comparison of the metal contents in the Rue leaves in this study showed that $\mathrm{Ca}$ contents are in higher amounts in the samples compared to the other heavy metals. A relatively higher amount of $\mathrm{Ca}$ in the leaves from all areas could be due to its higher natural abundance in the soil and the nature of Rue. In comparison to other sampling areas, Worabe is more exposed to human activity and the farms were used for long time, which could have significant contribution to gradual accumulation of metals in Rue farms through agricultural activities. This could be suggested as one of the reasons for the higher concentration of $\mathrm{Ca}$ determined in Worabe than others.

Metals uptake by plants may occur through different and complex biochemical processes. This uptake varies based on the ability of the plants to absorb metals from the soil, the availability of the mineral elements in soluble and absorbable forms, the abundance of specific metals at the specified site, the contamination level of the soil with heavy metals, etc. The variation of metal levels in soil, especially samples collected around Addis Ababa arises because of increasing industrialization and associated pollution of the biosphere, use of different types of fertilizers, pesticide treatment, and others are the main contributors. The use of sewage sludge, pesticides, irrigation of waters and fertilizers on agricultural land has made some of that land of questionable quality for production of food for humans and animals. The distribution and accumulation of metals in leaves of $R$. chalepensis L. are the reflection of the mineral composition of the soil and environment in which $R$. chalepensis L. plant grows. Therefore, the actual metal content of Rue varies considerably according to geographic origin, the use of fertilizers with different chemical compositions and other characterizing features such as water used for irrigation. Plants accumulate metals from the soil and environment in its different parts. However, this study focuses the level of metals in leaves of Rue because it is the leaves that are commonly consumed by users.

\section{Concentration of metals in Rue leaves collected from Kality}

As indicated in Table 5, Ca is in the highest amount with concentration of $2409 \pm 1 \mathrm{mg} / \mathrm{kg}$ followed by $\mathrm{Zn}(49.1 \pm 0.06 \mathrm{mg} / \mathrm{kg}), \mathrm{Cu}(5.76 \pm 0.06 \mathrm{mg} / \mathrm{kg}), \mathrm{Cr}(3.1 \pm 0.04 \mathrm{mg} / \mathrm{kg})$ and $\mathrm{Cd}$ $(2.87 \pm 0.03 \mathrm{mg} / \mathrm{kg})$ with the least concentration whereas, metals $\mathrm{Ni}$ and $\mathrm{Pb}$ are below detection limit. These results showed that the essential trace metals are found at higher amount whereas the non-essential in a lower amount or none. This is beneficial from the health point of view. Generally, the order of level of metals in rue leaves collected from Kality is: $\mathrm{Ca}>\mathrm{Zn}>\mathrm{Cu}>\mathrm{Cr}>\mathrm{Cd}$.

\section{Concentration of metals in rue leaves collected from Holeta}

In the Holeta samples $\mathrm{Ca}$ is in the highest amount with concentration of $1872 \pm 2 \mathrm{mg} / \mathrm{kg}$ followed by $\mathrm{Zn}(44.5 \pm 0.02 \mathrm{mg} / \mathrm{kg})$ and $\mathrm{Cr}(1.2 \pm 0.02 \mathrm{mg} / \mathrm{kg})$ with least concentration and the order of level of metals were found to be $\mathrm{Ca}>\mathrm{Zn}>\mathrm{Cr}$ in the Rue sample from Holeta. But, the other four metals $\mathrm{Cu}, \mathrm{Cd}, \mathrm{Ni}$ and $\mathrm{Pb}$ were observed below detection limit. 
Concentration of metals in rue leaves collected from Alem Bank

$\mathrm{Ca}$ is in the highest amount with concentration of $2443 \pm 2 \mathrm{mg} / \mathrm{kg}$ followed by $\mathrm{Zn}(60.8 \pm 0.5$ $\mathrm{mg} / \mathrm{kg}), \mathrm{Cu}(10.8 \pm 0.02 \mathrm{mg} / \mathrm{kg})$ and $\mathrm{Cr}(1.7 \pm 0.03 \mathrm{mg} / \mathrm{kg})$ and the order of the metals were found to be $\mathrm{Ca}>\mathrm{Zn}>\mathrm{Cr}$ in the Rue leaves collected from Alem Bank. However, the concentrations of metals such as $\mathrm{Cd}, \mathrm{Ni}$ and $\mathrm{Pb}$ were below detection limit of the instrument.

Concentration of metals in Rue leaves collected from Worabe

The last Rue leaf sample analyzed was collected from Worabe. Like the previous samples $\mathrm{Ca}$ is in the highest amount with the concentration of $3077 \pm 1 \mathrm{mg} / \mathrm{kg}$ followed by $\mathrm{Zn}$ with concentration of $63.9 \pm 0.1 \mathrm{mg} / \mathrm{kg}$. But, in this sample the concentrations of $\mathrm{Ca}$ and $\mathrm{Zn}$ are higher than those of the other three samples. In contrast to other sample sites, all the other five metals $\mathrm{Cr}, \mathrm{Cu}, \mathrm{Cd}, \mathrm{Ni}$ and $\mathrm{Pb}$ are below detection limit of the instrument.

Comparison of the concentration of metals in four different Rue samples

Figure 1 and 2 shows the comparative concentrations of metals in leaves of Rue collected from Kality, Holeta, Alem Bank and Worabe.

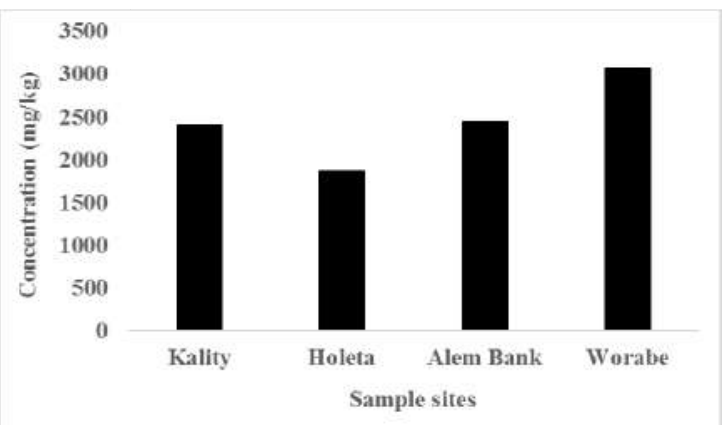

Figure 1. Bar graph summary of concentration of $\mathrm{Ca}$ in Rue leaves samples from Kality, Holeta, Alem Bank and Worabe samples.

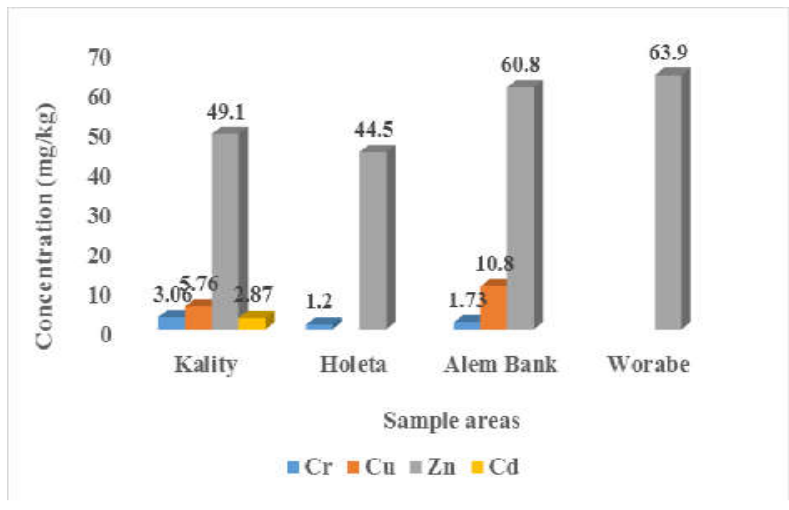

Figure 2. Bar graph summary of concentrations of $\mathrm{Cr}, \mathrm{Cu}, \mathrm{Zn}$ and $\mathrm{Cd}$ in Rue leaves samples from Kality, Holeta, Alem Bank and Worabe samples.

Bull. Chem. Soc. Ethiop. 2018, 32(2) 
From Figure 1 and 2 we can see that the trend of levels of metals concentration especially $\mathrm{Ca}$ and $\mathrm{Zn}$ in each sample is similar. Other metal contents are found to be quite different. In general, we can summarize that Rue sample from Worabe contains the highest amount Ca (3077 $\mathrm{mg} / \mathrm{kg})$ and $\mathrm{Zn}(63.9 \mathrm{mg} / \mathrm{kg})$ essential macro and micro nutrient, respectively, followed by Alem Bank, Kality and Holeta with the least concentration. Non-essential toxic metals such as Ni and $\mathrm{Pb}$ were found too low to be detected in all Rue samples, Cd was found too low to be detected in the three samples except samples from Kality and in contrast to other three sample sites Cr was found too low to be detected only in one sample site, i.e. Worabe.

Comparison of metal levels in leaves of Ruta chalepensis L. obtained in the present study with literature values

The results of this study were compared with the literature obtained from Jordan [4] and Ethiopia [28]. The levels of metals in Rue found in this study with the levels reported in the literature are given in Table $6[4,28]$.

As indicated in Table 6 the concentrations of $\mathrm{Ca}$ and $\mathrm{Cr}$ were not reported in Jordan Rue samples, hence they are not compared. The concentration of $\mathrm{Cu}$ is in the range of the values from Jordan $(5.55-9.38 \mathrm{mg} / \mathrm{kg}$ ) with the sample from Kality (Ethiopia) $(5.8 \mathrm{mg} / \mathrm{kg})$ and is in good agreement. However, the concentration of $\mathrm{Cu}$ in the sample from Alem Bank (Ethiopia) $(10.8 \mathrm{mg} / \mathrm{kg})$ is slightly higher than the range of concentration of $\mathrm{Cu}$ from Jordan $(5.55-9.38$ $\mathrm{mg} / \mathrm{kg}$ ) and its concentration is not detected in two sample sites in Ethiopia, which is different from the values from Jordan. The level the other metal Zn $(44.5-63.9 \mathrm{mg} / \mathrm{kg})$ from Ethiopia was found higher than the range of the reported data in Jordan (10.3-23.4 mg/kg). Except Rue samples from Kality the concentration of $\mathrm{Cd}$ was below detection limit in the other sample sites in Ethiopia, but its concentration $(2.9 \mathrm{mg} / \mathrm{kg})$ was found higher than the reported data from Jordan $(0.32-0.86 \mathrm{mg} / \mathrm{kg}$ ) and Ethiopia $(0.58-0.71 \mathrm{mg} / \mathrm{kg})$ [28]. The concentrations of nonessential toxic metals such as $\mathrm{Ni}$ and $\mathrm{Pb}$ were found below detection limit and this is different from the results reported from Jordan $(14.2-63.9 \mathrm{mg} / \mathrm{kg}$ ) [4] and Ethiopia $(0.17-1.42 \mathrm{mg} / \mathrm{kg})$ [28]. $\mathrm{Pb}$ was not detected in the present study because a less sensitive FAAS was used in the present study while it was detected and found in appreciable concentration in the earlier study from Ethiopia in which more sensitive GFAAA was used [28].

Table 6. Comparison of selected metal concentrations (mg/g, dry weight basis) in leaves of Rue samples of this study with reported values from literature.

\begin{tabular}{|c|c|c|c|}
\hline \multirow{2}{*}{ Metal } & \multicolumn{3}{|c|}{ Range of concentration of metals $(\mathrm{mg} / \mathrm{kg})$} \\
\cline { 2 - 4 } & Ethiopia & Jordan [4] & Ethiopia [28] \\
\hline $\mathrm{Ca}$ & $1872-3077$ & $\mathrm{NR}$ & $\mathrm{NR}$ \\
\hline $\mathrm{Cr}$ & $<\mathrm{DL}-3.1$ & $\mathrm{NR}$ & $\mathrm{NR}$ \\
\hline $\mathrm{Cu}$ & $<\mathrm{DL}-10.8$ & $5.55-9.38$ & $\mathrm{NR}$ \\
\hline $\mathrm{Zn}$ & $44.5-63.9$ & $10.3-23.4$ & $0.58-0.71$ \\
\hline $\mathrm{Cd}$ & $<\mathrm{DL}-2.9$ & $0.32-0.86$ & $\mathrm{NR}$ \\
\hline $\mathrm{Ni}$ & $<\mathrm{DL}$ & $0.45-3.17$ & $0.17-1.42$ \\
\hline $\mathrm{Pb}$ & $<\mathrm{DL}$ & $14.2-63.9$ & {$[32]$} \\
\hline Reference & This study & {$[4]$} & \multicolumn{2}{c|}{} \\
\hline
\end{tabular}

NR - not reported and DL - detection limit.

Generally, most of metal concentrations in Rue samples from Ethiopia differ slightly from concentration of Rue samples reported from Jordan. This might be due to differences in the geographical origin from where the Rue was cultivated. 
Comparison of selected metal concentrations $(\mathrm{mg} / \mathrm{g}$, dry weight basis) in leaves of Rue samples in this research with permissible values from $\mathrm{FAO} / \mathrm{WHO}$

The $\mathrm{Zn}$ concentration in the leaves of all the samples of $R$. chalepensis in this study ranges from $44.5-63.9 \mathrm{mg} / \mathrm{kg}$ and WHO recommended limit of $\mathrm{Zn}$ in plants is $50 \mathrm{mg} / \mathrm{kg}$ [31]. This indicates that the $\mathrm{Zn}$ concentrations in the leaves of $R$. chalepensis are below the permissible limit in Kality and Holeta samples but above the permissible limit in Alem Bank and Worabe samples.

The range of concentration of $\mathrm{Cu}$ in this study is $<\mathrm{DL}-10.8 \mathrm{mg} / \mathrm{kg}$, which is below the permissible limit of $\mathrm{Cu}$ for plants recommended by WHO, i.e. $10 \mathrm{mg} / \mathrm{kg}$ [32] and also below the permissible limits for $\mathrm{Cu}$ in medicinal plants according to WHO, i.e. $20 \mathrm{mg} / \mathrm{kg}$ [33]. For $\mathrm{Cr}$, the proposed limit set by WHO is $2 \mathrm{mg} / \mathrm{kg}$ [33], which is above the proposed limit set by WHO in Kality $(3.1 \mathrm{mg} / \mathrm{kg})$ sample and is below the proposed limit set by WHO in the other three samples.

For medicinal herbs the permissible limit for Cd set by WHO is $0.3 \mathrm{mg} / \mathrm{kg}$ [33]. Thus, Cd levels in the leaves of $R$. chalepensis in Ethiopian sample $(<\mathrm{DL}-2.9 \mathrm{mg} / \mathrm{kg})$ were below the permissible limit in the three samples collected from Holeta, Alem Bank and Worabe and above the permissible limit only in the sample collected from Kality. Metals $\mathrm{Ni}$ and $\mathrm{Pb}$ were not detected in all four Tena Adam samples from Ethiopia. Therefore, the levels of $\mathrm{Ni}$ and $\mathrm{Pb}$ in the leaves $R$. chalepensis in all samples in this study were below WHO prescribed limit of Ni (1.5 $\mathrm{mg} / \mathrm{kg})$ and $\mathrm{Pb}(10 \mathrm{mg} / \mathrm{kg})$ in medicinal herbs [33].

Generally, the level of most of selected metals found in the four Rue samples collected from four different areas of Ethiopia were found below maximum tolerable limits proposed by WHO. Thus, they are in safety baseline levels for human consumption.

\section{Analysis of variance (ANOVA)}

The variation in samples means come from different sources such as experimental procedure or heterogeneity among the samples (i.e. difference in mineral contents of soil, $\mathrm{pH}$ of soil, water, atmosphere; variation in application of agrochemicals like fertilizers, pesticides, etc. or other variations in cultivation procedures). In this study the variation in samples means of the analyte was tested whether they have significant difference or not by using ANOVA of single factor [29]. ANOVA at $\mathrm{p}=0.05$ indicated that there is significant difference among the sample means for the metals $\mathrm{Ca}, \mathrm{Cr}, \mathrm{Cu}$ and $\mathrm{Zn}$. This is due to variations in the other factors than in the experimental procedure. The source for this significant difference between sample means may be the difference in mineral contents of soil or $\mathrm{pH}$ of soil which predict the extent of mineral absorption by Rue plant. ANOVA of $\mathrm{Ni}$ and $\mathrm{Pb}$ and $\mathrm{Cr}$ were not done, since they were below detection limit of the instrument and found only in one sample respectively. Based on this description we can conclude that most of metals analyzed in this study were significantly different among the sampling sites.

\section{Pearson correlation of metals within Rue samples}

In this research, to correlate the effect of one metal concentration on the concentration of the other metal, the Pearson correlation matrices using correlation coefficient (r) for the samples were employed for metals determined in the samples [29] and presented in Table 7.

The results of Pearson correlation in Table 7 show that negative correlations are observed in the case of $\mathrm{Ca}$ (with $\mathrm{Cr}, \mathrm{Cu}$ and $\mathrm{Cd}$ ) and $\mathrm{Zn}$ with $\mathrm{Cd}$. These weak correlations indicating that the presence or absence of one metal affects the other metal in a lesser extent. As indicated in Table $7 \mathrm{Ca}$ with $\mathrm{Zn}, \mathrm{Cr}$ (with $\mathrm{Cu}, \mathrm{Zn}$ and $\mathrm{Cd}$ ) and $\mathrm{Cu}$ (with $\mathrm{Zn}$ and $\mathrm{Cd}$ ) shows positive correlation. These strong correlations may arise from common anthropogenic or natural sources as well as from similarity in chemical properties. In general, relatively good positive correlation is observed between $\mathrm{Cu}$ and $\mathrm{Zn}$. In contrast, weak correlation is observed between $\mathrm{Ca}$ and $\mathrm{Cr}$. 
Table 7. Pearson correlation matrices for metals in leaves of Ruta chalepensis L. samples

\begin{tabular}{|c|c|c|c|c|c|}
\hline Metal & $\mathrm{Ca}$ & $\mathrm{Cr}$ & $\mathrm{Cu}$ & $\mathrm{Zn}$ & $\mathrm{Cd}$ \\
\hline $\mathrm{Ca}$ & 1 & & & & \\
\hline $\mathrm{Cr}$ & -0.343 & 1 & & & \\
\hline $\mathrm{Cu}$ & -0.082 & 0.428 & 1 & & \\
\hline $\mathrm{Zn}$ & 0.530 & 0.078 & 0.555 & 1 & \\
\hline $\mathrm{Cd}$ & -0.061 & 0.292 & 0.185 & -0.260 & 1 \\
\hline
\end{tabular}

\section{CONCLUSION}

The optimized wet acid digestion method for the analysis of Rue leaf samples was found efficient as evaluated through the recovery test, which varied from 92.0 to $102 \%$ for all the metals. The levels of metals in Rue samples were found in the order: $\mathrm{Ca}(1872-3077 \mathrm{mg} / \mathrm{kg})>$ $\mathrm{Zn}(44.5-63.9 \mathrm{mg} / \mathrm{kg})>\mathrm{Cu}(<\mathrm{DL}-10.8 \mathrm{mg} / \mathrm{kg})>\mathrm{Cr}(<\mathrm{DL}-3.1 \mathrm{mg} / \mathrm{kg})>\mathrm{Cd}(<\mathrm{DL}-2.9 \mathrm{mg} / \mathrm{kg})$. The levels of metals in Rue samples determined and assessed for its quality comparing with permissible limits given by WHO and levels are in safety baseline levels for human consumption. Since, the concentration of was $\mathrm{Ca}$ higher, we can recommend that peoples who have deficiency of Ca can use Rue products in different ways. The levels of the non-essential toxic heavy metals $\mathrm{Ni}$ and $\mathrm{Pb}$ were found to be below the detection limits of the instrument. $\mathrm{Cd}$ was found in only one sample with low concentration and this is in a very good agreement with most of the results reported in other country.

Statistical analysis by using one-way ANOVA indicated that there is significant difference in mean concentrations of $\mathrm{Ca}, \mathrm{Cr}, \mathrm{Cu}$ and $\mathrm{Zn}$ in $R$. chalepensis $\mathrm{L}$. in the four sampling sites. This may be attributed to differences in soil composition, use of different fertilizers, pesticides, etc. Also, the results of Pearson correlation revealed that there is weak and/or moderate positive or negative correlation between metals with each other.

\section{ACKNOWLEDGEMENTS}

The authors are thankful to the Department of Chemistry of Addis Ababa University, Ethiopia, for providing the laboratory facilities. Solomon Admasu is thankful to the Ministry of Education for sponsoring his study.

\section{REFERENCES}

1. Moerman, D. Native American Enthobotany, Timber Press: Portand, USA; 1998.

2. Matu, E.N. Ruta chalepensis L. in PROTA (Plant Resources of Tropical Africa / Ressourcesvégétales de l'Afriquetropicale), Schmelzer, G.H.; Gurib-Fakim, A. (Eds.), Wageningen: Netherlands; 2011.

3. Asfaw, N.; Demissew, S. Aromatic Plants of Ethiopia, Shama Books: Addis Ababa, Ethiopia, 2009; pp 162-164.

4. Massadeh, A.M.; Abdul-Wahab, O.; El-Rjoob, A.-W.O.; Mohammad, N. Al-Omari, M.N. Assessment of heavy metals in different parts of Ruta chalepensis L. Rutaceae medicinal plant and soil samples collected from three selected zones in Jordan. Soil Sediment Contam. Int. J. 2016, 25, 587-596.

5. Fullas, F. Spice Plants in Ethiopia: Their Culinary and Medicinal Applications, Reference Publications, Inc.: Sioux City (USA); 2003; pp 133-137.

6. Holt, S. Tena Adam on Behance. Available at: http:/www.behance.net/gallery/65063/Tena Adam; Accessed on 15 October 2017.

7. Boulos L. Medicinal Plants of North Africa, Reference Publications, Inc.: Michigan (USA); 1983; p 158. 
8. Oyedele, D.J.; Asonugho, C.; Awotoye, O.O. Heavy metals in soils and accumulation by edible vegetables after phosphate fertilizer application. Electronic J. Environ. Agric. Food Chem. 2006, 5, 1446-1453.

9. Aiwonegbe, A.E.; Ikhuoria, E.U. Levels of selected heavy metals in some Nigerian vegetables. Trends Appl. Sci. Res. 2007, 2, 76-79.

10. Nnorom, I.C.; Osibanjo, O.; Ogugua, K. Trace heavy metal levels of some Bouillon cubes and food condiments readily consumed in Nigeria. Pak. J. Nutr. 2007, 6, 122-127.

11. Okator, E.C.; Nwajei, G.E. Metal contents in water and aquatic plant (Macaranga hendelotic) from Ororiner around Nigerian cement factory, Nkalagn. Res. J. Biol. Sci. 2007, $2,85-88$.

12. Ghdam, R.; Khanki, J.; Yunesian, M.; Mahvi, A.H.; Nazmara, S. Trace metal contaminants in Iranian flat breads. J. Agric. Social Sci. 2005, 1, 301-303.

13. Gulfraz, M.; Ahmed, T.; Afzal, H. Concentration levels of heavy and trace metals in the fish and Mangla lakes. Online J. Biol. Sci. 2001, 1, 414-416.

14. Weldegebriel, Y.; Chandravanshi, B.S.; Wondimu, T. Concentration levels of metals in vegetables grown in soils irrigated with river water in Addis Ababa, Ethiopia. Ecotoxicol. Environ. Safety 2012, 77, 57-63.

15. Kitata, R.B.; Chandravanshi, B.S. Concentration levels of major and trace metals in onion (Allium cepa L.) and irrigation water around Meki Town and Lake Ziway, Ethiopia. Bull. Chem. Soc. Ethiop. 2012, 26, 27-42.

16. Mekonnen, K.N.; Ambushe, A.A.; Chandravanshi, B.S.; Redi-Abshiro, M.; McCrindle, R.I. Assessment of potentially toxic elements in Swiss chard and sediment of Akaki River, Ethiopia. Toxicol. Environ. Chem. 2014, 96, 1501-1515.

17. Aregahegn, A.; Chandravanshi, B.S.; Atlabachew, M. Mineral contents of fruits of cactus pear (Opuntia ficus indica) grown in Ethiopia. Acta Hort. (ISHS), 2013, 979, 117-126.

18. Yami, S.G.; Chandravanshi, B.S.; Wondimu, T.; Abuye, C. Assessment of selected nutrients and toxic metals in fruits, soils and irrigation waters of Awara Melka and Nura Era farms, Ethiopia. Springer Plus, 2016, 5:747. DOI 10.1186/s40064-016-2382-3.

19. Endalamaw, F.D.; Chandravanshi, B.S. Levels of major and trace elements in fennel (Foeniculum vulgari Mill.) fruits cultivated in Ethiopia. Springer Plus, 2015, 4:5. DOI: 10.1186/2193-1801-4-5.

20. Wagesho, Y.; Chandravanshi, B.S. Levels of essential and non-essential metals in ginger (Zingiber officinale) cultivated in Ethiopia. Springer Plus, 2015, 4:107. DOI 10.1186/s40064-015-0899-5.

21. Mekassa, B.; Chandravanshi, B.S. Levels of selected essential and non-essential metals in seeds of korarima (Aframomum corrorima) cultivated in Ethiopia. Braz. J. Food Technol. 2015, 18, 102-111.

22. Hagos, M.; Chandravanshi, B.S. Levels of essential and non-essential metals in fenugreek seed (Trigonella Foenum-Graecum L.) cultivated in different parts of Ethiopia. Braz. J. Food Technol. 2016, 19, e2015059.

23. Abdella, A.; Chandravanshi, B.S.; Yohannes, W. Levels of selected metals in coriander (Coriandrum sativum L.) leaves cultivated in four different areas of Ethiopia. Chem. Int. 2018, 4, 189-197.

24. Tefera, M.; Chandravanshi, B.S. Assessment of metal contents in commercially available Ethiopian red pepper. Int. Food Res. J. 2018, 25, 989-1000.

25. Derbie, A.; Chandravanshi, B.S. Concentration levels of selected metals in the leaves of different species of thyme (T. schimperi and T. vulgaris) grown in Ethiopia. Biol. Trace Elem. Res. 2011, 141, 317-328.

26. Mekebo, D.; Chandravanshi, B.S. Levels of essential and non-essential metals in linseed (Linum usitatissimum) cultivated in Ethiopia. Bull. Chem. Soc. Ethiop. 2014, 28, 349-362. 
Levels of selected metals in the leaves of Ruta chalepensis L. (Rue) cultivated in Ethiopia 197

27. Gebre, A.; Chandravanshi, B.S. Levels of essential and non-essential metals in Rhamnus prinoides (Gesho) cultivated in Ethiopia. Bull. Chem. Soc. Ethiop. 2012, 26, 329-342.

28. Baye, H.; Hymete, A. Lead and cadmium accumulation in medicinal plants collected from environmentally different sites. Bull. Environ. Contam. Toxicol. 2010, 84, 197-201.

29. Miller, J.N.; Miller, J.C. Statistics and Chemometrics for Analytical Chemistry, 6th ed., Pearson Education Limited: Essex, England; 2010.

30. Skoog, D.A., West, D.M., Holler, F.J.; Crouch, S.R. Fundamentals of Analytical Chemistry. 8th ed., David Harries: USA; 2005; pp 720-723.

31. Shah, A.; Niaz, A.; Ullah, N.; Rehman, A.; Akhlaq, M.; Zakir, M.; Khan, M.S. Comparative study of heavy metals in soil and selected medicinal plants. J. Chem. 2013, 1-5.

32. Hassan, Z.; Anwar, Z.; Khattak, K.U; Islam, M.; Khan, R.U.; Khattak, J.Z.K. Civic pollution and its effect on water quality of river Toi at district Kohat, North-West Frontier Province (NWFP). Res. J. Environ. Earth Sci. 2012, 4, 334-339.

33. World Health Organization (WHO). Quality Control Methods for Medicinal Plant Materials, Revised, World Health Organization: Geneva; 2005. 